\title{
Influence of Customer Verbal Aggression on Turnover Intention
}

\author{
Xiaoyan LI \\ The Training Center of Dongfeng Motor Corporation, China \\ Special 1st Dongfeng Road, Wuhan Economic and Technological Development Zone, Dongfeng Motor \\ Corporation, Wuhan City, Hubei Province, China 430056
}

\begin{abstract}
Customer misbehaviors directed against service providers results in negative emotional responses and work withdrawal behavior for service workers. This study examined several relationships pertaining to customer verbal aggression, employee emotional labor strategies, and turnover intention. Results of hierarchical linear models revealed that employee turnover intention increased when an employee encountered customer verbal aggression; however, both surface acting and deep acting mediated this effect.
\end{abstract}

KEYWORD: Customer verbal aggression; Turnover intention; Emotional labor strategy

\section{INTRODUCTION}

Historically, scholars have focused primarily on the workplace aggression between intra-organization members and their associated job tasks (Bryant, 2010; Hershcovis, \& Barling, 2010; Rayner, Hoel, \& Cooper, 2002; Tepper, 2000). Yet in all of these studies, there is a lack of focus up on nonorganizational members (e.g., customers). We are particularly interested in the verbal forms of aggression (e.g., yelling, insults and cursing) because they are the most frequently experienced forms of customer aggression (Barling, Rogers, \& Kelloway, 2001; Glomb, 2002). Several researchers have suggested that withdrawal behaviors may be an outcome of emotional labor (e.g., Brotheridge \& Lee, 2003; Grandey, 2000; Rubin, Tardino, Daus, \& Munz, 2005). Previous research has also demonstrated that emotional labor influences turnover intention (e.g., Wong \& Law, 2002), with no empirical data to examine the mediating effect of emotional labor strategies between customer verbal aggression and turnover intention.

\section{DEVELOPMENT OF HYPOTHESES}

Customer verbal aggression consumes employee emotional resources. The service providers often disguises or modifies their actual emotions in order to express what is required by their job role and to protect themselves from further abuse or turnover intention (Hochschild, 1983; Ashforth \& Humphrey, 1993). Hochschild $(1979,1983)$ distinguished forms of emotional labor: surface acting, deep acting and automatic regulation (see also Grandey, 2000).

Hypothesis1.Customer verbal aggression relates to emotional labor strategies.

Hypothesis2.Customer verbal aggression positively relates to employee turnover intention.

Hypothesis3. Emotional labor strategies will partially mediate the relationship between customer verbal aggression and employee turnover intention.

\section{METHOD}

\subsection{Sample}

Three hundred and sixty two front-line workers in call centers in China completed a survey over a onemonth period. Approximately $90 \%$ were women and $10 \%$ were men, and on average they were 24.20 years old $(\mathrm{SD}=2.43)$.

\subsection{Measures}

Participants rated each item using a 5-point Likert scale (5="Strongly Agree"; 1="Strongly Disagree").

Customer verbal aggression. Two existing scales for measuring customer verbal aggression were borrowed by Dormann and Zapf (2004) and by Skarlicki, Jaarsveld and Walker (2008).

Turnover intention. Turnover intention was measured using a three-item scale developed by Benttein and Vandenberg (2005).

Emotional Labor Strategies. Diefendorff, Croyle and Gosserand (2005) measure emotional labor strategies by 14 items. 


\section{RESULTS}

Hypothesis 1a predicts that customer verbal aggression is associated with increased daily surface acting within individuals while Hypothesis $1 \mathrm{~b}$ predicts that customer verbal aggression is associated with decreased daily deep acting within individuals. Hypothesis 1c predicts that customer verbal aggression is associated with decreased automatic regulation within individuals. Table 1 provides the results of the HLM regressions testing hypotheses 1a, $1 \mathrm{~b}$ and 1c. Customer verbal aggression was positively associated with surface acting $\left(b_{10}=0.24\right.$, $\mathrm{p}<0.001)$ and negatively associated with deep acting $\left(b_{10}=-0.18, \quad p<0.001\right)$ but was not significantly associated with automatic regulation $\left(b_{10}=-0.09, \mathrm{~ns}\right)$; thus supporting Hypothesis 1a and Hypothesis $1 \mathrm{~b}$ but not Hypothesis 1c.

Table 1 HLM Results Predicting Surface Acting, Deep Acting, and Automatic Regulation

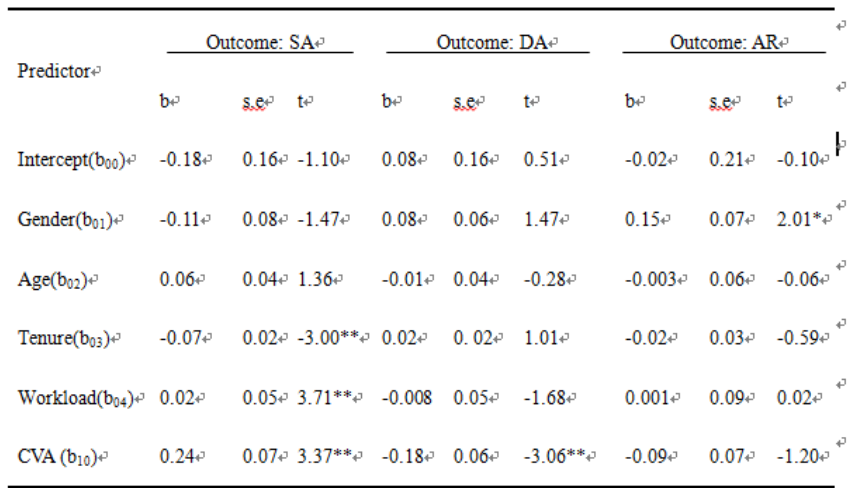

Note. CVA means customer verbal aggression; SA means surface acting; DA means deep acting; AR means automatic regulation. $* \mathrm{p}<.05, * * \mathrm{p}<.01$

Hypothesis 2 predicts customer verbal aggression positively relates to employee turnover intention. Table 2 provides the results of the HLM regressions testing the hypotheses. Customer verbal aggression was positively associated with employee turnover intention $\left(b_{10}=0.30, p<0.001\right)$. Thus, Hypotheses 2 was supported.

Hypothesis $3 \mathrm{a}$ predicts that surface acting partially mediates the within-individual relationship between customer verbal aggression and turnover intention, and Hypothesis $3 \mathrm{~b}$ predicts that deep acting partially mediates the within-individual relationship between customer verbal aggression and turnover intention. Hypothesis $3 \mathrm{c}$ predicts that automatic regulation partially mediates the withinindividual relationship between customer verbal aggression and turnover intention. Table 2 provides the results of HLM regression testing of these hypotheses. As shown in Table 2 , surface acting $\left(b_{20}\right.$ $=0.18, \mathrm{p}<0.01)$ and deep acting $\left(\mathrm{b}_{30}=-0.15, \mathrm{p}<0.001\right)$ were significantly associated with turnover intention, and the coefficients for customer verbal aggression decreased slightly when these emotional labor strategies were controlled. However, the former statement does not hold for automatic regulation $\left(b_{40}=-0.04, n s\right)$. To specifically determine which relationships were mediated, we examined the significance of the indirect effects of customer verbal aggression on turnover intention through emotional labor strategies. Results of our analyses revealed a significant indirect affect from customer verbal aggression to turnover intention through surface acting $(\mathrm{z}=2.40, \mathrm{p}<0.05)$ and deep acting $(\mathrm{z}=2.15$, $\mathrm{p}<0.05)$. The indirect effects of customer verbal aggression on turnover intention through automatic regulation were not significant. Thus, Hypotheses 3a and $3 \mathrm{~b}$, but not $3 \mathrm{c}$, were supported.

Table2 HLM Results Predicting Turnover Intention

\begin{tabular}{|c|c|c|c|c|c|c|c|c|c|c|c|c|}
\hline \multirow{2}{*}{ redictor } & \multicolumn{11}{|c|}{ Direct Effects Model Mediated Model } & \multirow[b]{2}{*}{$\mathrm{t}$} \\
\hline & $b$ & se & $\mathrm{t}$ & $b$ & 5. & $\mathrm{t}$ & $b$ & sep & $\mathrm{t}$ & $b$ & 5.8 & \\
\hline Interc & 2.74 & .26 & $\begin{array}{l}10.54 \\
* *\end{array}$ & 2.78 & .27 & $\begin{array}{l}10.38 \\
* *\end{array}$ & 2.77 & .26 & $\begin{array}{l}10.8 \\
* *\end{array}$ & 2.73 & .26 & $\begin{array}{l}10.69 \\
* *\end{array}$ \\
\hline Gender $\left(b_{01}\right)$ & -0.01 & .10 & 0.06 & -0.03 & .10 & -0.03 & 0.02 & .10 & 0.16 & 0.02 & .10 & 0.16 \\
\hline $\operatorname{Age}\left(b_{02}\right)$ & 0.12 & .07 & 1.76 & 0.11 & .07 & 1.53 & 0.11 & .07 & 1.61 & 0.11 & .07 & 1.65 \\
\hline Tenure $\left(b_{03}\right)$ & -0.04 & .03 & -1.36 & -0.05 & .03 & -1.40 & -0.04 & .03 & -1.38 & -0.04 & .03 & -1.28 \\
\hline Workload $\left(b_{0}\right)+$ & 0.01 & .01 & 1.52 & 0.01 & .01 & 1.61 & 0.01 & .08 & 1.38 & 0.12 & .08 & 1.48 \\
\hline $\operatorname{CVA}\left(b_{10}\right)$ & 0.30 & .06 & $\begin{array}{l}4.67 \\
* *_{j}\end{array}$ & 0.23 & .06 & $\begin{array}{l}3.64 \\
* *_{j}\end{array}$ & 0.27 & .06 & $\begin{array}{l}4.86 \\
* *\end{array}$ & 0.29 & .06 & $\begin{array}{l}4.82 \\
* *\end{array}$ \\
\hline $\mathrm{SA}\left(\mathrm{b}_{20}\right)+$ & 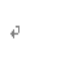 & 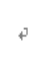 & + & 0.18 & .06 & $\begin{array}{l}3.06 \\
* *\end{array}$ & 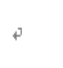 & P & $\checkmark$ & P & 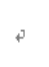 & 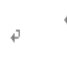 \\
\hline $\mathrm{DA}\left(\mathrm{b}_{30}\right)$ & + & + & + & 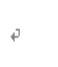 & 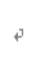 & 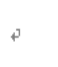 & -0.15 & .06 & $\begin{array}{l}-2.67 \\
* *\end{array}$ & 5 & $P$ & 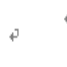 \\
\hline $\operatorname{AR}\left(b_{40}\right)$ & s & s & 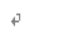 & ? & ? & s & $\$$ & 3 & 8 & -0.04 & .05 & -0.85 \\
\hline
\end{tabular}

Note. CVA means customer verbal aggression; SA means surface acting; DA means deep acting; AR means automatic regulation. $* \mathrm{p}<.05, * * \mathrm{p}<.01$

\section{DISCUSSION}

Our results have several important theoretical implications. First, we extend employee working pressure to the customer domain by developing and testing a theoretical model of the effects of customer verbal aggression on employee turnover intention. The empirical results showed that customer verbal aggression influenced service employees' emotional labor strategies and turnover intention. Stress caused by customer aggression should be the most direct and important reason to explain employee turnover intention. However, most existing research pertaining to customer-employee interaction focuses on how employee attitudes and behaviors impact customer loyalty and satisfaction (Liao \& Chuang, 2004; Schneider, Ehrhart, Mayer, Saltz, \& NilesJolly, 2005). Little is known about how customer behavior affects employee emotion and behavior. In this study, both direct and indirect effects of customer verbal aggression were considered to predict employee turnover intention. We have expanded the body of research pertaining to turnover, 
especially regarding the Price-Mueller (2000) model. As we know, the Price-Mueller model (2000) is one of the most widely accepted theoretical models (Mueller\& Price 1990; Price, 2001, 2004) used when conducting turnover research. Price (2001) stated that further research was necessary to discover new explanatory variables to explain employee turnover. This study answered the call and extended PriceMueller model.

Furthermore, our work identified that different emotional labor strategies have different impacts on turnover intention. Prior research has revealed that surface acting, rather than deep acting, is positively associated with personal costs such as emotional exhaustion, physical complaint, and burnout (for a meta-analysis, see Bono \& Vey, 2005). On the other hand, prior research has failed to identify a positive relationship between deep acting and turnover intention. In response, our study identified how surface acting positively relates to turnover intention, while deep acting negatively relates to turnover intention. The possible reason for this discrepancy is that deep acting leads to internalization of one's job role and, hence, reduces dissonance between felt and displayed emotions (e.g. Brotheridge \& Grandey, 2002; Grandey, 2003; Brotheridge \& Lee, 2003). The same kind of counteracting effect has been previously proposed for deep acting in relation to its reduction of emotional dissonance and increase of psychological effort (Grandey, 2003). The results further demonstrate that the resource-based perspective provides useful guidance for studying the effects of customer-related social stressors on employee emotion and behavior.

\section{REFERENCES}

[1] Bryant, M. R. (2010). Dealing with violence in the workplace. Society for Human Resource Management, 18(1), 23-29.

[2] Diefendorff, J. M., Croyle, M. H., \& Gosserand, R. H. (2005). The dimensionality and antecedents of emotional labor strategies. Journal of Vocational Behavior, 66(2), 339-359.

[3] Grandey, A. A. (2003). When "the show must go on": Surface and deep acting as determinants of emotional exhaustion and peer-rated service delivery. Academy of Management Journal, 46(1), 86-96.

[4] Grandey, A. A., Dickter, D. N., \& Sin, H.-P. (2004). The customer is not always right: Customer aggression and emotion regulation of service employees. Journal of Organizational Behavior, 25(3), 397- 418.

[5] Hershcovis, M.S., \& Barling, J. (2010). Towards a multifoci approach to workplace aggression. A meta-analytic review of outcomes from different perpetrators. Journal of Organizational Behavior, 31(1), 24-44.

[6] McCance, A. S., Nye, C. D., Wang, L., Jones, K. S., \& Chiu, C. (2010). Alleviating the burden of emotional labor: the role of social sharing. Journal of Management, 9(1), 125.

[7] Price J. L. (2001). Reflections on the determinants of voluntary turnover. International Journal of Manpower, 22(7), 600-624.

[8] Schata. A. C.H., \& Frone M R. (2011). Exposure to psychological aggression at work and job performance: The mediating role of job attitudes and personal health. Work \& Stress, 25(1), 23-40.

[9] Yagil, D. (2008). When the customer is wrong: A review of research on aggression and sexual harassment in service encounters. Aggression and Violent Behavior, 13(2), 141152. 